\title{
2006-902: RESTRUCTURING OF CE4506 (ENVIRONMENTAL POLICY AND POLLUTION PREVENTION DESIGN) AND STUDENT RESPONSE SURVEY
}

\section{Michelle Jarvie, Michigan Technological University}

Michelle Jarvie is a Ph.D. Candidate in Environmental Engineering at Michigan Technological University. She has a B.S. in Environmental Engineering and an M.S. in Environmental Policy. Prior to her current studies, she worked for two years as a consulting engineer on the city of Detroit's water system. She has also worked as a civil engineer for the National Park Service, and advised Denali National Park on their wastewater treatment. Her dissertation is on the biodegradation of the natural estrogens estrone and estradiol in sewer systems. She is committed to excellence in teaching, and will be available for academic positions that start in the fall of 2007. 


\title{
Restructuring of CE4506 (Environmental Policy and Pollution Prevention Design) and Student Response Survey
}

\begin{abstract}
This paper details the format change of a senior level environmental policy and pollution prevention class offered to 51 civil and environmental engineering students in Spring of 2005. The old format entailed 3 lecture hours per week, and traditional hour exams. The new format included class room strategies for active and collaborative learning, had no exams, and reduced the lecture to one class hour each week. The paper includes qualitative results from a survey regarding student preferences for the new class structure in comparison to the previous structure.
\end{abstract}

\section{Background}

Historically, engineering education has been dominated by a lecture only format, in which students are expected to retain and memorize lecture material, reproducing it on demand for exams ${ }^{1}$. This one-way transfer of information from teacher to student has been termed the "banking concept of education" by Paulo Freire $^{2}$.

In the 1970's Feire criticized "banking education" for its inability to actively involve the students as critical thinkers. Freire viewed banking education as a form of domination, in which the teacher maintained total control over the lecture material, and the students became intellectually unengaged, passive recipients of facts.

As an alternative to banking education, Freire suggested that modern educators should utilize dialogue within the class, creating an environment that develops critical thinking and focuses on education as a process of inquiry. In this new pedagogy, teachers and students would become co-investigators about the subject at hand. The roles would become more fluid, with teachers learning from students and students learning from teachers. Freire emphasized the fundamental importance of dialogue in education, writing "Without dialogue there is no communication. And without communication there can be no true education" Freire believed that banking education was a means of dominance, which required the passive acceptance of facts by students. He proposed that education should be a practice of freedom, engaging students to become involved in class and critically examine the material at hand.

Currently, many engineering educators are unknowingly practicing Freire's liberation pedagogy through the inclusion of active learning techniques. Active learning has been "generally defined as any instructional method that engages students in the learning process" ". As Freire called for, active learning includes 
students as engaged participants in learning, rather than passive recipients of facts.

One type of active learning is collaborative learning, which may include "any instructional method in which students work together in small groups toward a common goal" ". A key element of collaborative learning is student interactions. The goal of collaborative learning is for students to grow beyond rote memorization, by questioning the material and its application, and develop a deeper understanding of the meaning of class material. In fact, it has been proposed that the goal of education itself is to "induce students to develop a deep approach to subjects"1. This questioning and deeper understanding are the building blocks of Freire's pedagogy of freedom.

As paraphrased from Felder \& Brent, classroom strategies that can foster "deep approach" to learning possess the following characteristics, among others:

- Interest in and background knowledge of the subject

- Assessment that emphasizes conceptual understanding

- Long-term engagement with learning tasks

- Opportunities to exercise reasonable choice in the content and method of study ${ }^{1}$

The terms cooperative and collaborative learning are often used interchangeably. Smith et. al., make a distinction between cooperative and collaborative learning in that "cooperative learning requires carefully structured individual accountability, while collaborative does not" ${ }^{\text {. }}$. Regardless of whether it is cooperative or collaborative, working together requires students to develop the interpersonal communication and team building skills required for success in the engineering work place ${ }^{5}$. In the professional engineering world, communication skills are required in the three forms of written, oral, and graphic communication ${ }^{6}$.

This article focuses on the restructuring of a class from the traditional "banking education" approach, to include elements of a more progressive active learning approach. Collaborative formal discussion groups and research projects provided active learning experiences, which included written, oral, and graphic communication.

\section{History of Class format:}

CE4506 Environmental Regulation and Pollution Prevention design has been taught for several years at Michigan Technological University. From 2002-2004, CE4506 was taught each spring by different departmental faculty or staff. The class was taught mostly in the traditional "banking education" format of a lecture class with the course grade based on a few home work assignments and exams. 
In Spring 2005, the course was restructured and offered to 51 civil and environmental engineering juniors and seniors. Students were surveyed half way through the semester to determine student preference between the new structure and the old. Although these students had not taken this specific course under the old structure, the majority of the classes in their engineering curriculum would have exposed them to the "banking education" format. Thus, it is valuable to gather information regarding students' preference with regard to the new course structure.

\section{New Structure:}

In Spring of 2005, CE4506 was team taught by two new instructors. Instructor A was a professional engineer at a local firm. Instructor $\mathrm{B}$ was a $\mathrm{Ph}$. $\mathrm{D}$. candidate in Environmental Engineering at Michigan Tech. The two instructors rotated on a weekly basis. Thus, each taught every other week. The class was taught on Monday, Wednesday, and Friday, in one hour sessions. Course format changes included alterations to the components of the student grade and the classroom teaching methods as described in the following sections.

\subsection{Student Grade Components}

Student grades for the class were based on the following components:

- Weekly quizzes $(40 \%)$

- Research project on the application of environmental regulations for a specific contamination site or persistent environmental problem:

○ Paper (15\%)

- In-class presentation $(10 \%)$

- Research project on a specific pollution prevention technology:

○ Paper (15\%)

$\circ$ In-class presentation $(10 \%)$

- Class participation (10\%)

Quizzes were administered each Friday. The weekly quizzes were based on material covered in Monday's lecture and case studies discussed in class on Wednesday. Quiz results were promptly returned to students to provide timely feedback. As faculty feedback has been related to student's self-reported gains from classes ${ }^{7}$. The intention of quizzes was to provide incentive for attendance and routine feedback to the students (and the instructors) regarding the students' grasp of the course material.

The first research project was due at midterm. The students were expected to work in pairs to research an environmental problem (or specific contamination site), the regulations that pertained to the problem, and the application of the regulations for this problem. The second research project was due at the end of the semester. Again in pairs, the students were expected to research a sustainable 
pollution prevention technology, and explain what environmental problem it relieved, how it was developed, and how it worked. Presentations accompanying each of these projects were performed in class on Fridays throughout the semester. The students had approximately 7 weeks to complete each project.

The research projects were included in the place of formal exams, as a tool to assess the students' understanding of the course material and improve the students' written communication skills. Students were asked to propose their own research subjects for instructor approval, and encouraged to select topics they found interesting. The research assignments met the previously mentioned aspects of tools that foster a "deep approach" to learning. By choosing the subjects themselves, students tailored assignments to their own interests. If students did not choose subjects for which they already had some background knowledge, this knowledge was surely gained through their research. The research paper was intended as a venue where students could convey their conceptual understanding of the course material. Additionally, the research papers required a relatively long term engagement of 7 weeks. By selecting their own topic and research methods, the students exercised choice in the content and method of study. Thus, the research projects were likely candidates for fostering a deep understanding of the course material.

Attendance was taken each Wednesday, to ensure students were attending discussion days. Participation points were assigned for attendance and for each time a student took a leadership role in the group, as described in section 3.2.

\subsection{Classroom Format}

The first alteration to classroom format was the reduction of lecture hours from three-per-week to one-per-week. The weekly lecture was always presented on Monday. This served as an introduction to the week's topic and provided background information for that week's case study and group discussions. Background knowledge of the subject has been listed as one of the elements that can lead to a deep learning approach among students ${ }^{1}$. As the traditional lecture format will only capture the interest of students with a reproducing orientation to learning (i.e. memorization) ${ }^{1}$, lecture hours were reduced to make time for other, active learning techniques, while still providing a foundation of background knowledge for each week's subject.

The second alteration to the classroom format was the addition of one group discussion hour each Wednesday. It was anticipated that group discussion with meaningful dialogue would be difficult with 51 students. Thus, the first Wednesday of the class, students were asked to form discussion groups of 6-7 students each. The groups were capped at 7 because when groups become much larger than 6 students, it is more likely that some students will become passive observers in the group, and students tend to have less sense of responsibility to larger groups ${ }^{8}$. Eight groups were formed. The first discussion day, group bonding 
was facilitated by introductions and ice-breaker activities. To encourage group ownership, the students were each asked to name their discussion groups. The following group names were chosen:

\author{
Crazy 8's \\ The Planeteers \\ Civility, Hostility, and the Notorious Yankee Swap \\ I Got Worms \\ C-Blerb Run \\ The A-Team \\ Booze-Hounds \\ JJ-Talk
}

Each Monday, students were assigned out-of-classroom research and reading to be done as preparation for Wednesday's discussion groups. For example, when the Superfund cleanup process was lectured about on Monday, students were required to locate and read the Record of Decision (ROD) for a site near their home communities. The ROD is a public document that explains which alternatives will be used to clean up a Superfund site. The ROD is based on scientific and engineering information gathered during two other processes: Remedial Investigation and Feasibility Study. Students were also required to locate and read the Remedial Investigation and Feasibility Study for their chosen site. This material would be brought to class for group discussion as to whether the students' agreed with the ROD for each case based on the information gathered.

Student involvement and leadership of the discussion groups was considered key to the success of the discussion groups. Thus, each group was to have a rotating group leader, with each student required to lead their group twice during the semester. The role of the leader was to attend class with prepared discussion topics and questions (in writing) for the subject at hand, facilitate group discussion, take notes on group discussion, take attendance of all the group members, and submit all of this information to the instructor. Participation points were based on this information. Discussion days were included as a technique to promote dialogue about the course material, improve student verbal communication skills, encourage student leadership, allow for reasonable student control over the subjects discussed, and promote a deeper understanding of the course material.

Fridays were reserved for student presentations of their research projects, and weekly quizzes. Student presentations, with a required Power Point slides, were included as a method to develop the verbal and graphic communication skills of the students. Additionally, as the course subject had a wide range of application to unique circumstances, the presentations were intended to give the students a sense of the myriad of ways in which both environmental policies and pollution control technologies can be applied in varying situations. These presentations were 
intended to enrich the class material with numerous "real world" examples of the application of the course concepts that would be difficult for the instructors to research in the normal time allowed for class room preparation.

\section{Findings \& Discussion:}

Qualitative methods are used to gather data about human perspectives ${ }^{9}$. Surveys are an established qualitative method for capturing data about students' perceptions of engineering classroom experiences ${ }^{9-10}$. An open ended survey was administered half way through the semester to gather information regarding preference about the new class structure in comparison to the old structure. The survey was administered in class. Although there were 51 students in the course, only 41 students responded to the survey. The remaining ten included students that were absent that day and students that did not respond to the survey. The surveys were anonymous, but letter identification was assigned to each survey (A through NN) for purposes of identifying each respondent uniquely during qualitative data analysis. The survey is presented in Appendix A.

The results presented in this section are based upon qualitative analysis of the responses to each survey question. Upon examination of the surveys, student preferences for the following were revealed: reduced lecture hours, the inclusion of one discussion hour per week, preference for research papers and presentations over exams, and student acceptance of a grade based on quizzes papers and presentations.

\subsection{Student Preference for the Reduced Lecture Hours:}

The first survey question inquired as to whether students believed one lecture hour per week was adequate, or if the students preferred the traditional format of three hours per week. Of the 41 students surveyed, only two expressed criticism of the decreased number of lecture hours. However, even those students criticizing the Monday lecture did not express a preference for three lecture hours per week. Thus, none of the students surveyed expressed a preference for the traditional format.

Displeasure with the reduced lecture format was expressed by Student A in the following words:

Having just (one) lecture hour a week cuts down on the topic detail and number of topics discussed.

Student A expressed a concern for lost lecture topics and depth. However, several students indicated a deeper level of intellectual engagement during discussion periods, as opposed to traditional lectures. In this format, the lectures were intended as an introduction to each week's topic. The preparatory assignments and discussion days were intended as a venue where a deeper conceptual understanding of the week's topic could be gained. In fact, cutting the lecture 
hours by $2 / 3$ must result in less material conveyed in this format. But it is arguable that these topics were covered in much greater detail through group discussions and research projects, which, as previously discussed, possess characteristics which promote a deep approach to learning.

Three students $(\mathrm{T}, \mathrm{V}, \mathrm{W})$ commented that they preferred the reduced lecture format specifically because of the inclusion of the group discussions. Student T explained that s/he did not prefer three lecture hours per week because "I enjoy being able to discuss things and explore on my own", indicating that this student was more engaged in the new class format. While Student V stated:

I feel that I get a pretty good idea of the topic by one lecture, and then discussing it on Wednesday helps to give a practical application of the regulations.

This statement confirms that, for some students, the class format did reinforce and add depth to the lecture material. Student $E$ also expressed that Monday lectures served as a good introduction to the topic of the week:

I think the Monday lectures are good because it prepares you for the rest of the week

As a new topic was covered each week, lecture and discussion days were paired, with each lecture introducing a subject for out of class room research/reading and in class discussion. In effect, Monday lectures functioned as an introduction to concepts to be explored more in depth on Wednesdays. A cohesive subject for the lecture and discussion days is an essential element in the success of this format.

The only other criticism of the reduced lecture format was given by Student DD as follows:

\section{Monday lectures are sufficient, although sometimes rushed.}

With the reduction in lecture hours, it is likely that the instructors did rush lectures in an effort to provide a comprehensive introduction to each new topic. However, students may have been aided in their retention of faster lectures by reviewing lecture slides electronically accessible to all (the departmental R-drive), as expressed by student $\mathrm{U}$ :

I feel like I'm learning enough in the one lecture period especially since I can review the lectures on the $R$-drive.

One final reason, expressed by three students $(\mathrm{N}, \mathrm{S}, \mathrm{X})$, for preferring the reduced lecture format, was that it was more interesting than the traditional format.

Student $\mathrm{N}$ explained that the new format was "more interesting than three lecture hours per week". While Student S explained, "This way is something different 
and makes it more interesting. When asked specifically about three lecture hours per week, Student S replied "every other class is like that" and student X replied "Three lecture hours becomes monotonous".

Overall, students indicated a preference for the reduced lecture format. Despite the two criticisms of this format, none of the 41 students surveyed indicated a preference for the three-lecture-per week format. Students indicated an increased understanding of the application of the course material was gained through the added discussion sessions. Additionally, the new structure, with fewer lectures, was more interesting to the students than the traditional format. The inclusion of collaborative learning through student-lead discussion groups made the class more appealing than lectures alone.

\subsection{Student Preference for the Inclusion of a Group Discussion Hour:}

The second survey question inquired as to whether Wednesday discussions improved student understanding. As discussion days usually required the students to perform some research and reading on their own and bring the materials into class, students were asked if they preferred this work to traditional graded homework assignments,

Only one student in the class expressed a desire not to have in class discussions. In the words of student A:

\section{I feel that I get very little from the discussions and would prefer to write a} memo on my findings.

It should be noted that Student A was the only student that indicated a preference for not including group discussion days in the class format. Thus, 40 if the 41 students surveyed expressed a preference for including weekly discussions. Recall that Student A also expressed a concern, discussed earlier, for a loss of lecture topics and detail with the reduced format. These statements indicate that Student a may perceive the traditional "banking education" lecture format as providing more facts to the students, or that this student has a reproduction orientation to learning. However, the aim of this course was not rote memorization of environmental law, but for the students to gain a conceptual understanding of the investigation and application of environmental regulations and sustainable pollution control technology. In fact, several students indicated that the preparatory assignments and discussions provided a greater understanding of the application of the course material.

Four students (V, T, U, and KK) specifically mentioned the value of the research assignments performed in preparation for discussion days. In the words of Student $\mathrm{V}$ : 
I think looking up stuff relating to the topic and then discussing it really shows how those reg(ulation)s apply to the real world.

While student $\mathrm{U}$ explained:

I love the discussions. They not only allow me to see practical applications of the reg(ulation)s but also familiarize me with how to find the info...

Thus, it is not only the discussions themselves, but the preparatory out of class room reading and research that enriched the students' learning. Despite the fact that the assignments accompanying discussions were found useful to those who did them, two students, $\mathrm{O}$ and F, specifically mentioned that it was difficult to be motivated to prepare for discussion as there was no classroom check on student preparedness. Future attempts at teaching this course could easily be adapted so that preparatory materials brought to discussion days were handed in to the instructor and included in the course grade component. This may provide increased student motivation to complete preparatory assignments for discussion days.

In total, 13 students (EE, U, O, NN, CC, C, E, AA, X, Z, DD, W, N) specifically mentioned that the discussions aided in understanding of the application of the course material or increased learning. Student E described discussions as:

gets you involved and talking about the topics which helps me to learn better.

While student $\mathrm{NN}$ explained about discussions: application

It makes the information sink in well through the use of real-life

These statements both reflect increased student learning through the discussions themselves. Thus, the students found both the preparatory assignments and the discussions as tools that increased their understanding of the course material.

Student leadership of the discussion groups resulted in no complaints. In fact, only one student commented negatively on the discussion group format, in the words of Student $\mathrm{H}$ :

Discussions should be better formatted. Sometimes it is hard to talk about certain topics. We need to have some other thought provoking questions as well.

This student was the only one who requested additional discussion aides beyond what the student group leader provided. However, Student $\mathrm{H}$ did not express direct criticism of the student leadership, merely a request for additional 
assistance. Additional discussion points and questions could easily be prepared by an instructor for each discussion day. However, these materials should be used sparingly. One of the elements that make the discussion groups likely candidates to foster deep learning is the ability of the students to exercise control over the discussions themselves. By providing students with scripted discussion topics, the students would be lead through the exploration process, rather than develop a true investigative approach to learning on their own.

Three students (P, N, II) explained that they preferred discussion days because they found discussions interesting when compared to traditional lectures. In the words of student II:

It is both interesting and fairly fun.

Overall, the students expressed a preference for the inclusion of discussion days in the class format. They indicated that the research/reading assignments followed by discussions created a deeper conceptual understanding of the application of the course material. The students also found the discussion days more interesting than traditional lectures.

\subsection{Student Preference for Research Papers and Presentations:}

The third survey question inquired about the usefulness of research papers and presentations for enriching the students' understanding of the course material, and whether the students would prefer traditional exams in place of these assignments.

Only two students (Q and $\mathrm{HH}$ ) stated that they would prefer exams. One, Student $\mathrm{Q}$, explained, "I would prefer exams over presentations, but I like the research papers".

Student Q expressed displeasure with the knowledge gained from the research assignment:

These papers/presentations, as far as individual research is concerned, do not give us a full scope of the reg(ulation)s. I would prefer traditional exams if they help to show me the real work situations and how I would apply the reg(ulation)s.

It should be noted that only student Q expressed this displeasure with the research paper and presentations. This student expressed a desire to be tested on the way the regulations would be applied in a work setting. However, the application of environmental regulations is site-specific, with no one answer that would be applicable to all circumstances. The student presentations of research assignments were intended to enrich to the class with many examples of the application of 
environmental regulations. In fact, several students stated that the reason they preferred the papers were that they were more in depth than exams and that watching each other's presentations exposed them to more real world examples. Overall, 39 of the 41 students surveyed expressed a preference for research papers and presentations over exams.

In total, 19 students $(\mathrm{K}, \mathrm{H}, \mathrm{Y}, \mathrm{A}, \mathrm{CC}, \mathrm{E}, \mathrm{I}, \mathrm{O}, \mathrm{R}, \mathrm{S}, \mathrm{U}, \mathrm{V}, \mathrm{AA}, \mathrm{BB}, \mathrm{DD}, \mathrm{FF}, \mathrm{II}, \mathrm{JJ}$, $\mathrm{NN})$ specifically mentioned learning more detail, or gaining a greater understanding of the regulations and their applications through the research paper assignment. In the words of student R:

The research has us learn and understand the law, as opposed to just memorizing them.

While Student AA explained:

I think this method is better than exams because application of the material is required more than just repeating the info.

And Student E stated:

By doing research you get a better understanding of the material. It is not just memorizing something.

The statements above indicate a deeper understanding of the course material was provided by the research papers in comparison to the memorization required for traditional exams. It exemplifies the student preference for deeper learning over "banking education" methods.

Additionally, several students stated that listening to other's presentations in class gave them a sense of how environmental regulations could be applied in various settings. In the words if Student U:

The research projects are better than exams. I get in depth knowledge of my topic plus all the other groups topics.

While Student JJ explained:

Not only do we still learn the course material, but we get to hear 15 or so different applications of them, exams = bad!

These statements reflect that students valued the presentation for reasons beyond the experience in presenting itself. The In fact, none of the students mentioned increased presentation skills as part of the value of this assignment. The students valued the presentations for their ability to learn from each other the wide variety of ways that environmental regulations are applied. 
Of those who mentioned learning gains from the research papers, four students ( $\mathrm{K}, \mathrm{H}, \mathrm{Y}, \mathrm{CC})$ cited a preference for research papers because of the "real world" examples the brought to the class. As Student CC explains:

The papers and presentations are good because you see the real world applications to topics as opposed to just memorizing for exams. I feel I have a more thorough understanding because of them.

In the words of student Y:

The presentations allow us to see many real world situations that exams just can't cover.

While Student H said:

I do not prefer traditional exams. Paper/Presentation allows me to see the real world applications instead of just memorizing facts.

Once again, the theme of deeper understanding of the course material is raised by Student CC. Additionally, both Students $\mathrm{CC}$ and $\mathrm{H}$ referred to exams as requiring "just memorizing", indicating displeasure with the knowledge gained from the banking approach to education. "Real world" examples brought to the class through the presentations of research projects assisted students in developing a deeper understanding of the course material by highlighting its application in a variety of circumstances.

A final reason for the preference of research papers over exams was that the students could tailor the assignments their own interest by choosing environmental contamination sites from their home towns, or environmental contamination related to a hobby. For example, one student chose to do a research project on lead contamination in surface water near shooting ranges. Eight Students (F, KK, N, T, P, W, X, EE) specifically cited the ability to research a topic of interest to themselves as a reason for preferring research papers. Student F explained:

Projects allow research in an area of interest to me, and let me learn the material as a practical matter, not just to pass an exam.

Student W stated:

I prefer the presentations because it gives me the chance to go in depth on a topic of my interest and learn a lot about it.

While Student P said: 
The method once again allows the student to narrow into an interest while still gaining an understanding of the class topics.

These statements reflect that the students preferred the research projects because of their ability to choose their own research subject. In fact, it would be impossible for any faculty member to tailor an assignment that would interest 51 students simultaneously. Allowing the students to exercise choice in their research subjects can result in assignments that captivate the interest of the whole class. As the class was composed of engineering students from two disciplines (civil and environmental engineering), this strategy allowed each student to focus on applying the course material to their own field, and may be a successful strategy when dealing with multidisciplinary classrooms.

Overwhelmingly, the students expressed a preference for the inclusion of the research paper and presentation over traditional exams. Students indicated a deeper conceptual knowledge gained of the application of course materials both from researching their own papers and from listening to each other's presentations. Students specifically valued the "real world" examples brought to the class from this assignment. The students indicated valuing the opportunity to choose research topics of interest to themselves. Additionally, students indicated displeasure at the memorization required for traditional exams.

\subsection{Student Acceptance of Quizzes, Papers, and Presentation as Grade Components}

The fourth question on the survey inquired whether grading based on quizzes, papers, and presentations appropriately measured student performance in the class. Only one student offered any criticism or complaints of the elements that made up the class grade. Student HH replied:

The quizzes are easy and the presentations/papers don't reflect all the course material.

Recall that Student HH earlier expressed a preference for exams over presentations. This student may perceive rote memorization as knowledge gained, and possess a reproducing orientation to learning. The aim of the papers and the quizzes as assessment tools was not to for students to demonstrate the memorization of facts, but for students to demonstrate a conceptual knowledge of the application of the course material. Thus, many details discussed in class would not be reflected in the quizzes.

In total, 40 of the 41 students surveyed approved of the course grade components. Overwhelmingly, the students praised weekly quizzes as a tool for enforcing attendance and reinforcing lecture material. Ten students (KK, E, Y, W, F, X, AA, DD, FF, Z) specifically mentioned useful aspects of the quizzes. Student $\mathrm{E}$ explains the incentive quizzes provide for attendance as follows: 
You have to always attend class and keep up on your work.

While Student KK explained:

What is taught on Monday is quizzed on Friday. This helps (us to) know how much we retain.

These students repeatedly cited retention and reinforcement of lecture material as results of the weekly quizzes. The quizzes also were considered a powerful motivator for weekly class attendance. It is not only important that class material captivate and engage students, but that they are motivated to participate in class. Weekly quizzes worked to prevent a pattern of falling behind in class material, or lack of attendance. As a result, quizzes proved a motivator for student involvement in the class.

Six students (Z, Y, F, X, AA, DD) specifically mentioned the ability of papers and presentations to develop and demonstrate a deeper knowledge of the class material. In the words of Student Y:

In order to write papers and give presentations you have to have a better understanding of the subject.

While student DD explained:

Projects show applications of material learned.

These students expressed that the papers were a place where more detailed knowledge and application of the course concepts could be conveyed.

Overall, the students approved of the course grade components. Recall that in earlier the students expressed a perception of traditional exams as requiring "just memorization" rather than fostering a deeper learning approach. Despite the students' opinions of exams, the quizzes were praised for reinforcing the course material and enforcing class attendance. Thus, students not only valued an increased depth of knowledge, they also wanted to retain class information. Quizzes were valued for information retention, while the research papers were valued for the development and demonstration of a deeper understanding of course material.

\section{Conclusion}

As the results presented in Section 4 indicate, the students expressed an almost unanimous preference for the new format, including the following elements: 
- No students expressed preference for the old class format when compared to the reduced lecture format.

- 40 of 41 students surveyed preferred inclusion of a weekly group discussion hour.

- 39 of 41 students surveyed preferred research papers and presentations over traditional exams.

- 40 of 41 students surveyed approved of the course grade components.

Reasons students cited for accepting this class format can be broken into two broad categories including: depth of knowledge and student interest.

The students indicated that preparatory assignments and discussion days were well coupled to add a greater understanding of each week's lecture topic. The students also stated that the discussion days were "more fun" and it was "easier to pay attention" on these days than in a traditional lecture.

The student response to the research papers and presentations indicated the wealth of "real world" examples brought to the through the presentations themselves and an increased depth of knowledge from researching the papers. Students also valued the papers for the ability to choose a subject of interests to themselves.

It should also be noted that there were almost as many comments purporting the increased depth of knowledge due to research projects (19 comments) when compared to group discussions and preparatory assignments (17 comments indicating increased depth of knowledge). Thus, students found both the research projects and discussions to be elements that increased their learning.

However, there were more than twice the comments related to preferring papers because of increased interest ( 8 comments) as compared to finding discussions interesting (3 comments). Students lead the discussion days, but did not specifically choose the topics to discuss, as these were based on each week's lecture. More choice was exercised over the content of the research projects than the discussions. This indicates that when it comes to capturing student interest, choice in content may be an important factor.

A few key alterations to the discussion days were suggested by the students that may increase motivation for preparation and quality of discussion. The preparatory research and reading assignments required for discussion days could be collected and included in the course grade component. This may provide greater incentive for students to attend discussion days prepared. Alternate discussion questions could be prepared by the instructor, to enrich the quality of discussions. However, these should be used sparingly, as student control over the discussion content was a key component that may foster a deep learning approach. 
In conclusion, the students overwhelmingly preferred the reduced lecture format with the inclusion of active and collaborative learning techniques as opposed to a traditional banking education approach to the course. Students specifically noted an increased interest in the course and assignments and a deeper understanding of the application of course material provided by new class room methods.

\section{Appendix A}

\section{CE4506 Survey}

1. Have the Monday lectures been adequate to explain the weekly class topics? Would you prefer a tradition format of three lecture hours per week?

2. Do the Wednesday discussions improve your understanding of the topics? Discussion days usually require some student preparation prior to coming to class. Do you prefer these assignments to traditional homework?

3. This class replaces exams with two research papers and presentations. Please comment on the usefulness of these assignments and presentations as tools to enrich your understanding of the course material. Would you prefer traditional exams?

4. Do you feel that being graded on the quizzes, papers, and presentations adequately and appropriately measures your performance in the class? Explain.

\section{Bibliography:}

1. Felder R M., Brent, R., “Understanding Student Differences,” Journal of Engineering Education, Jan 2005, pp. 57-72.

2. Freire, P. Pedagogy of the Oppressed, New York: The Continuum, Publishing Company, 1970.

3. Prince, M., "Does Active Learning Work? A Review of the Research," Journal of Engineering Education, July 2004, pp. 223-231.

4. Smith, K A., Sheppard, S.D., Johnson, D.W., Johnson, R. T., "Pedagogies of Engagement: Classroom-Based Practices.” Journal of Engineering Education, Jan 2005, pp. 87-101.

5. Pappas, E. C., Kampke, S. L., Hendricks, R. W., Kander, R. G., “Am Assessment Analysis Methodology and Its Application to an Advanced Engineering Communications Program," Journal of Engineering Education, July 2004, pp. 233-146.

6. Lengsfeld, C. S., Edelstein, G., Black, J., Hightower, N., Root, M., Stevens, K., Whitt, M. "Engineering Concepts and Communication: A Two-quarter Course Sequence," Journal of Engineering Education, Jan 2004, pp. 79-85. 
7. Bjorklund, S. A., Parente, J. M., Sathianathan, D., Effects of faculty Interaction and Feedback on Gains in Student Skills," Journal of Engineering Education, April 2004, pp. 153-159.

8. Davis, B. G., Tools for Teaching, San Francisco: Jossey-Bass A Wiley Company, 2001.

9. Leydens, J. A., Moskal, B. M., Pavelich, M. J., "Qualitative Methods Used in the Assessment of Engineering Education," Journal of Engineering Education, Jan 2004, pp. 65-71.

10. Olds, B. M., Moskal, B. M, Miller, R. L., "Assessment in Engineering Eductation: Evaluation, Approaches and Future Collaborations," Journal of Engineering Education, Jan 2005, pp. 13-25. 


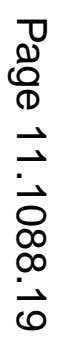

